\title{
THE CHALLENGES OF IMPLEMENTING ROBOTIC PROCESS AUTOMATION IN GLOBAL BUSINESS SERVICES
}

\author{
Dahlia Fernandez* \\ Faculty of Technology Management and Business, Universiti Tun Hussein Onn Malaysia
}

Aini Aman

Faculty of Economics and Management, Universiti Kebangsaan Malaysia

\begin{abstract}
Organizations use a variety of automation tools to simplify their tasks. One of the tools is Robotic Process Automation (RPA). Recently the issues of the less-than-successful use of the system have been raised. To address this issue, the aim of this study is to understand the challenges of implementing RPA in Global Business Services (GBS) industry. The study is conducted using an in-depth case study approach and interviews at one of the world's largest oil and gas organizations in the GBS industry. The result of the study showed that the organization is facing various challenges and issues during and after implementing the RPA technology in their organization. Amongst the challenges are the limitation of the task that can be automated, system failure, and safety and data privacy issues. The study suggested that good planning during the implementation of RPA and a strong security team are crucial in solving the challenges faced by the organization.
\end{abstract}

Keywords: Robotic Process Automation; Global Business Services; challenges; system failure; safety

Received: 4 May 2020

Accepted: 31 July 2021

https://doi.org/10.33736/ijbs.4301.2021

\section{INTRODUCTION}

Identifying and understanding the challenges that come with the implementation of Robotic Process Automation (RPA) technology is crucial, as having a clear understanding of the issues can help organizations to propose new ideas in addressing these matters. It also helps to channel the facts through physical exploration of RPA technology itself, which is said to be easy to implement, but it has many limitations that need to be addressed. Hence, this leads to the purpose of this study which is to understand the challenges of implementing RPA in the Global Business Services (GBS) industry. To achieve this objective, this study was conducted using semistructured interviews in the world's largest oil and gas company that has been implementing and using RPA technology for four years.

\footnotetext{
- Corresponding author: Faculty of Technology Management and Business, Universiti Tun Hussein Onn Malaysia, 86400 Batu Pahat, Johor, Malaysia. Email: dahliafernandez111@gmail.com
} 
The remainder of the paper is structured as follows. The next section of this paper which is a literature review will give an overview of GBS industry and is followed with the definition of RPA and its challenges based on previous studies. Next, the research methodology is presented, followed by the findings of the study with evidence from the extract of the interview transcript. The fourth section is the discussion based on the findings. The final section of this paper provides the conclusion of the study.

\section{LITERATURE REVIEW}

\subsection{Global Business Services (GBS)}

Over the past few decades, many organizations have outsourced some of their business processes to other firms to achieve cost savings. Diversification is a contractual agreement in which the principal requires the contractor to perform certain tasks, such as part or all the production process, employment services, or as a support function (Wirtz et al., 2015). Although there are various benefits to be gained from outsourcing, there are some organizations that still do not want to outsource their processes to third parties due to performance and privacy risks (Aman, 2016). These firms subsequently created regional or functional partnerships.

Today, the GBS industry has become increasingly popular. Compared to traditional models of shared services and outsourcing services, the GBS model is different (Wirtz et al., 2015). GBS exists when various processes and functions are shared within a global entity that operates in one unit, with the goal of achieving scalability, reducing costs, and leveraging processes. Organizations use third-party provider services for strategic function, while maintaining ownership control for part of the operations process (Fernandez \& Aman, 2018). It is a service integration made from the most competitive strategies that leverage information and communications technology, finance and accounting, human resources, and engineering design services (Aman, 2016). It has been an important tool in driving and complementing the partnership services approach as many organizations are applying GBS strategies to align business objectives and achieve economic scale. To enhance the performance of the organization, GBS companies undertake various strategies including the use of new technology within the organization, the latest of which is RPA.

\subsection{Robotic Process Automation (RPA)}

The article published by The Financial Express (2016) defines RPA as a set of automation software tools used by firms for repetitive processing and low-end tasks without any human involvement. In addition, Bataller et al. (2017) defined RPA as a method, system and tool, including computer programs encoded in computer storage, to automate manual processes. Method, system and tool include actions to identify processes that are manually performed by users interacting with computers and automate those processes by a robot that is tasked to interact with another computer. According to Lacity and Willcocks (2015), RPA is an easy-toconfigure system where users of systems that perform business operations can execute it without the need for programming and users can be trained to independently automate processes in just a few weeks. 
Based on these definitions, in this study, RPA is defined as a business process automation system that uses software tools to interact with existing applications and replace humans. This humansubstituted RPA software is referred to as a "swivel chair" process in which humans take inputs from a set of systems (e.g., email), process those inputs, and then input the output into a record system (e.g., ERP) (see Figure 1).

Figure 1: RPA software and RPA swivel chair (Willcocks et al., 2015)

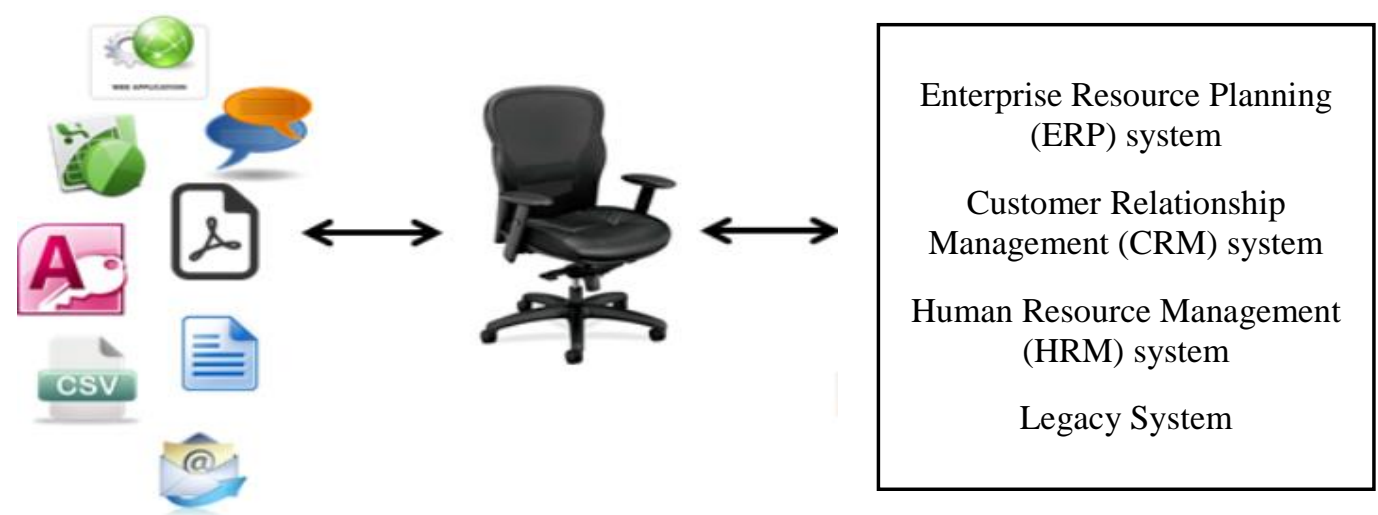

RPA gives significant impacts on individual and organization (Fernandez \& Aman, 2018). RPA provides organizations with the opportunity to save money and upsurge process efficiency by automating certain mundane and repetitive tasks. It also provides better work quality and accuracy (Lacity \& Wilcocks, 2015; 2016).

However, despite many advantages of RPA, there are many risks and challenges that can be faced by any organizations. One of the challenges is RPA is not suitable for every single task. A skill and a correct approach are needed in identifying processes that are appropriate to be automated (Lacity \& Willcocks, 2016). RPA is used to automate more simple work including rules-based tasks with precise guidelines (Rozario \& Vasarhelyi, 2018; Lacity \& Willcocks, 2016). A correct process must be selected as all processes are not fit for RPA. Organizations must look for easy wins when embarking on their RPA journey. They must try to avoid choosing a complex and subjective process (Rozario \& Vasarhelyi, 2018).

Besides that, RPA is functioning between different systems and web applications (e.g. ERP) which requires existing infrastructure to be built on heavyweight IT solutions (Penttinen et. al., 2018). In addition, when automating a certain task, the inputs are required to be in digital format and all the process required a rules-based step (Asatiani \& Penttinen, 2016). Any mistake made during the coding process will cause a widespread error throughout the organization and will leads to many mistakes and serious consequences (Agaton \& Swedberg, 2018; Burnett et al., 2018; Lacity et al., 2015). 
Nevertheless, another main issue of RPA is safety and data privacy. It is important to ensure sensitive data is not misused. Many firms are failing to consider the security risks. A robot working by itself can do anything a human can do, including accessing databases and manipulating services. However, a malicious robot can execute tasks that harm an organization. Part of the problem is that bots by nature need to access business data. In many cases, this information will be sensitive and must be protected. In addition, the bots will be using an organization's credentials to log in, so they will need access to passwords. If not properly secured, unauthorized access to an RPA system could result in a serious consequence (Lacity \& Willcocks, 2018; Willcocks et al., 2015).

\section{METHODOLOGY}

A qualitative approach is used to carry out this study. The qualitative research approach is very different from the quantitative approach because it uses an inductive process approach. The qualitative research approach is a systematic way to understand people and the nature of transactions between them and the environment (Ormston et al., 2014). Typically, this approach involves a small, unambiguous and focused sample size. Moreover, according to Jacks (2017), qualitative methods are suitable for studies using the lens of the theory of institutional logic, since the context of the theory requires greater emphasis and focus (Yin, 2013).

In accordance with the objective of the study of understanding the challenges of implementing RPA in the GBS industry, this study has selected a single case study methodology, since it provides a detailed and in-depth understanding of the topics under investigation (Yin, 2013). This study uses a single case study methodology to investigate case-based research because RPA is relatively new and is still not widely used in the GBS industry in Malaysia. One of the world's largest oil and gas organizations in the GBS industry was selected for this study. The company has been selected based on purposive sampling which involves the selection of individuals or companies that are proficient and well-informed with the implementation of RPA in the GBS industry (Patton, 2002). In addition, this method is useful to show the uniqueness of a case and allow researchers to understand a real-world topic and create research results and theories in a practical way (Yin, 2011). This method can also provide information on a topic by presenting the elements studied in an environment from the perspective of the researcher (Yin, 2011). Furthermore, a single case study can help researchers understand the issues in all levels of management at the selected company.

However, this method requires careful investigation to avoid biases and maximize research so that it can be carried out in more detail (Walsham, 2006). Researchers must personally participate in the collection of data and interviews with various stakeholders to obtain different points of view and opinions based on various methods used by Walsham (2006). Qualitative data is gathered through semi-structured interviews with various respondents that are involved in the implementation process of the RPA system in finance and accounting (F\&A) unit. All the interviews were recorded and copied verbatim according to the category in the framework as a guide to analyse the challenges of RPA (Ismail et al., 2016; Walsham, 2006). Once the transcription process is complete, researchers identified the issues and themes that were constantly identified by repeated transcript readings. Table 1 lists the details of respondents. The interview with the respondents lasted 25 hours. 
Table 1: Details of Interviews

\begin{tabular}{clcc}
\hline & \multirow{2}{*}{ Name and Position } & \multicolumn{2}{c}{ Interview Session } \\
\cline { 3 - 4 } & Vice President of Finance and Accounting & 1 & Duration (Hour) \\
\hline & Unit & 2 & 1 \\
2 & Vice President of Revenue Unit & 1 & 3 \\
3 & Human Resource Manager & 2 & 2 \\
4 & Operational Manager & 1 & 4 \\
5 & Team Manager 1 & 1 & 2 \\
6 & Team Manager 2 & 1 & 2 \\
7 & Team Manager 3 & 1 & 1 \\
8 & Finance Operation Specialist 1 & 1 & 2 \\
9 & Continuous Improvement Manager 1 & 1 & 1.5 \\
10 & Continuous Improvement Manager 2 & 1 & 1 \\
11 & Continuous Improvement Manager 3 & 1 & 1 \\
12 & Finance Operation Specialist 2 & 1 & 1.5 \\
13 & Finance Operation Specialist 3 & 1 & 1.5 \\
14 & System Control Manager & & 1.5 \\
\hline
\end{tabular}

\section{RESULTS AND DISCUSSION}

Even though RPA provides many potential benefits and eliminates human intervention, however, there are still some challenges faced after the implementation of RPA. In this section, the findings and analysis are discussed according to the research question developed, which is what are the challenges faced in the GBS industry in implementing RPA. There are three main challenges that will be discussed in this section which are the type of task that can be automated, system failure, and safety and data privacy.

\subsection{Type of Task That Can Be Automated}

The process of identifying proper cases for implementation of the RPA software seemed most suitable where the degree of process standardization and documentation, transaction volumes, rules-based process, and process maturity is significantly high (Willcocks et al., 2015).

“..it should not involve any cognitive decisions that require the human judgement because the robots just follow the algorithm” - Continuous Improvement Manager 1

“...you can't automate everything. You can automate the types of work that do not require human judgement. That's just a straightforward process that's repetitive; those are the types of work that you can automate" - Continuous Improvement Manager 2

Besides, due to the limitation in the type of work that can be automated, it will lead to difficulty during the process of designing and coding the manual task towards automation. According to a 
project team manager, based on her experience she sees the needs for the task to be eliminated, simplified and standardized first before they move to the process of automation.

"as I said, we need to eliminate, simplify and standardize before even jump into automation. If your current process is not standardized and simplified, and it would be a big challenge when you try to deploy it because you must know robot cannot think as human, so whatever you instruct them to do, they will just follow, and the more steps you have, the more complicated and it will drag the projects, and even you will receive a lot of challenges from maybe design team" Team Manager 1

Hence, they tried to avoid the difficulties when they are automating the manual task by making sure that these three steps which are to eliminate, simplify, and standardize are followed. This approach is acknowledged by Continuous Improvement Manager 1 and is explained in detail.

"Probably the risk is that people might jump into just automating processes right away and that's not what we want. What we want people to do is eliminate those unnecessary or non-valueadding steps; simplify the processes in terms of how it is being executed and standardize the process across the different units or workgroups before you decide or before you really embark in terms of an automation journey because the risk is that if the process is inefficient in the current state and you automate right away; then, you will just be automating inefficiencies in the system. So, we try to avoid that by ensuring that there is a total review of the process to ensure that we identify this as opportunities before implementing robotics" - Continuous Improvement Manager 1 .

Besides that, if any minor error is made in the encoding process, the error will lead to a widespread error in the organization. This is stated by Continuous Improvement Manager 2;

“...I think another risk could be the risk of error because I think we make... we, we are really robust in terms of how we set up the programming and the robust process steps, etc. But I guess if there is an error, that error could become systematic in nature. So, it could become a very widespread error..." - Continuous Improvement Manager 2.

All of these showed that the RPA still needs human support. Humans are the only ones who can determine processes suitable for automation and monitor the performance of the robots.

\subsection{System Failure}

System failures are common to any organization that has just implemented a new system (Fernandez et al., 2018). However, the way in which the management overcomes and reacts to the failure of the system has had a major impact on the success of the system.

According to Team Manager 1, some of the failures of the system were due to the failure of the system as tested. This is because, at the time of real implementation, the system does not have the ability to control large amounts of data. This is one of the risks involved due to weaknesses in system design in the early stages. 
"Another part will be system capability. When we do system testing and all that it is always in a non-production environment. We can never have near to a close production environment. Where for example I go to the system I get a tester to test, everybody says performance is okay. When I go live, we have a few thousand users in the network, suddenly the system so slow and hang. So how could we bounce back to this kind of performance and challenges? Those are the things that any project team is afraid of..." - Team Manager 1.

Besides, one of the main causes of system failure is due to an error in the system configuration process. According to Team Manager 2;

"... and there are times that we even forgot to set decimal point. So, we thought by setting a tolerance of RM1, so, whatever more or less than RM1, you can just clear. You do not need to ask our permission or remain open. But what if 1.01? So, 1.01 is like the 2 decimal points that we forgot to set the logic, and the robot just does not work..." - Team Manager 2.

This is possible because the RPA still has limitations in the absence of human judgment. Currently, RPA technology in the organization has not fully utilized artificial intelligence (AI). Because of this, the robot is still unable to apply the logic that humans have in handling the assigned tasks.

"It's more on the understanding of us or including developer on a robot. So, we must have that kind of mindset that robots cannot think at all. So, you must set and spoon-feed everything, but sometimes we just thought that they can capture, and they cannot. So, I think this is only a fun part of it that you must learn how to communicate and understand how robot works" - Team Manager 1

Additionally, products within the RPA category often contain analytics features and a central platform for maintaining and controlling all the bots deployed across the organization (Morrison, 2019). Therefore, it can lead to external factors problems in the use of RPA including internet problems in the control center. The RPA control center is located in another country. To connect the organization from different countries, they need a strong internet connection. However, when the internet connection is weak or malfunctioning, it will affect the organization to operate smoothly.

"Then, they say it's Wi-Fi connectivity or Internet connectivity issue. Then, we cannot fix that because it's out of our control that we cannot control the Internet speed and...and the connection" - Continuous Improvement Manager 3.

In addition, system failures are also caused by external factors such as the absence of electricity in the control center. According to Team Manager 1;

"So, if that 7 am there is a power failure or something goes wrong that robot does not do the job, so someone has to trigger. So we need somebody to control and check on the programmed that has been set for the robot" - Team Manager 1.

In addition, although RPA does not require human intervention in its task process, it still requires humans to control the robot in the event of any problems. However, when the robot is working 
on a public holiday, and in the event of system failure, the robot cannot function on that day until it is repaired, or the problem is resolved by the workman on duty. This problem is acknowledged by Continuous Improvement Manager 2;

“...but we've had some issues recently around what happens on a public holiday if there's an issue in the control room; we've got fewer people; how do we ensure that the passwords are renewed at the right time; how does that all work..." - Continuous Improvement Manager 2.

Furthermore, some of the issues that caused problems in the RPA technology were due to human error in which technical personnel operating in another country forgot to turn on the robot and failed to update the password causing the RPA system to fail that day. According to Continuous Improvement Manager 3;

“...but the system failure personally that I see that we encounter is more related to human, like they forget to update the password, didn't turn on the robot on time, and things like that..." Continuous Improvement Manager 3.

Other than that, one of the specialists in the F\&A unit stated the importance of knowledge when dealing with the robot. Knowledge is crucial in the implementation and usage of the robot. According to her, she is having a problem when she just started to work in the organization since she has no knowledge of managing the RPA especially if there is a system failure or any technical error.

"The other disadvantage is robots as much as they are great, they are robots, they are machines; things can go wrong. Robots can do some you know, things can go wrong and especially if they are new robots like Prime and things like that; if something goes wrong, we are still very new we don't know what the issue is, so that might delay task a little bit." - Finance Operation Specialist 1 .

\subsection{Safety and Data Privacy}

The third aspect found in the challenges of implementing RPA is regarding safety and data privacy. RPA facilitates mundane and repetitive tasks, but it also has the potential to bring security risks. According to Emma, there are many risks faced by the organization in implementing RPA such as data privacy and security issues. A robust control system and good planning are required in order to mitigate the risks.

"I think some of the other risks are around the data privacy, the security, the risk of cyberattacks but I think we have a very robust control system in place and a framework that looks at all of these risks at the beginning when we're assessing the opportunity and whether it's right for our RPA" - Continuous Improvement Manager 2.

Despite the impacts that RPA can have, there are still many tasks that need human intervention. The technology is not yet able to be operated without human. Human are still needed for controlling and monitoring the robot. Human intervention is important in making sure that the robot is safe to be used and the data are well kept. According to Team Manager 1; 
"... we still need to put people in place to check on the robot. To check that the robot there is nobody hacking in, deactivate what the robot has done, there is no illegal change to the programme of what the robot can do, we have to be very careful about that"-Team Manager 1.

Besides that, it is crucial for the organization to know how to handle sensitive data since it is critical and needs to be safeguarded. The organization must take into account what data every employee may or may not have access to. According to Continuous Improvement Manager 1;

"So, there's another risk that probably a third, really last one is in terms of ensuring that you have adequate controls in handling sensitive information and putting controls to ensure that only the right level of access is provided to people in terms of saying the people handling the bots. So that they will not be able to tamper in terms of commercial-sensitive information or probably restrict access to these kinds of data" - Continuous Improvement Manager 1.

RPA still needs support from humans to be successfully implemented. The technology is not yet able to operate without human intervention nor is it able to reproduce the higher-level thinking and actions of which humans are capable.

Figure 2 shows the concept map for the challenges of implementing RPA. 
Figure 2: Concept Map for the Challenges of Implementing RPA

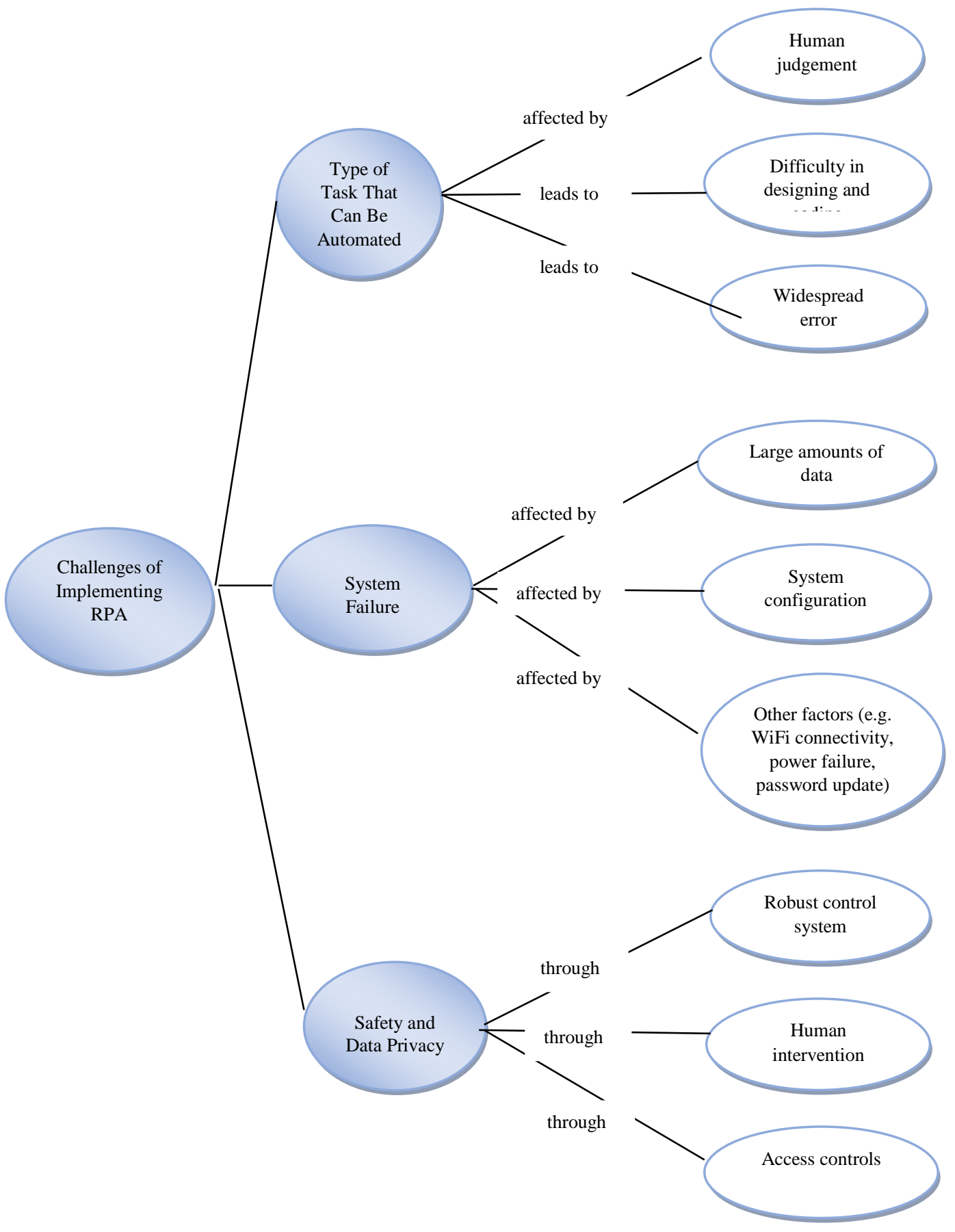




\section{DISCUSSION}

The results of this study showed that the process to be automated must have sufficient volume and transactions, as high-volume transactions allow for better opportunities for organizations to obtain cost savings. In addition, the study also found that rules-based processes are better to automate. This is because RPA still needs a thorough guide to completing certain tasks (Rozario et al., 2018; Lacity \& Willcocks, 2016). Furthermore, organizations should target more mature processes as the process is more stable and predictable which in turn has a lower risk of automation (Rozario et al., 2018; Lacity \& Willcocks, 2016).

Besides that, the results showed that there is a risk when the RPA does the job incorrectly and causes a change of context which in turn can affect the quality of work in the GBS organization. This may go unnoticed for some time, leading to widespread misconduct to the organization. This finding is in line with Agaton and Swedberg (2018), Burnett et al. (2018), and Lacity et al. (2015) who stated that widespread errors will result in many inaccuracies and bring serious consequences to the organization. For example, some respondents stated that during the robot configuration process, they forgot to place the decimal point which caused the system failure to occur. Therefore, details during the robot development process and control of robot operations should be emphasized. This is because although robots are easy to develop, however, they are not the same as humans, who can interpret and adapt in a situation if necessary.

In addition, respondents also stated that during the configuration process, they should think like robots. This is because robots cannot make judgments like humans. From a technical perspective, RPA is not so different from other forms of enterprise automation that have existed for decades. Although RPA may be a new trend in the current market, the implementation strategy, and development and control measures are still the same as other technologies. Support from various units, development strategies, and a more thorough risk assessment process should be done. This will help in reducing the risk of system failure and ensure a smoother work process in the GBS organization.

The main purpose of the organization using RPA in business is because of its ability to reduce the risk of errors inherent in human work. Even so, RPA itself should address data security and privacy risks (Lacity \& Willcocks, 2018; Willcocks et al., 2015). There are many procedures that can be done automatically in the F\&A unit in the GBS industry such as invoice processing, credit management, file transfer, and other processes. All these processes require RPA to have confidential and private data such as customer credit card information, bank accounts, passwords, addresses, and other personal and financial information in the database. This shows that the F\&A unit in the GBS industry keeps a variety of confidential and important data for the organization. These data should be protected from any misuse, misrepresentation and fraud. For this reason, security risk management is a priority issue in the implementation of RPA in the GBS organization. The most important issue is to ensure that confidential data is not misused through the privileges granted to software robots or from those who operate and control the system. Security measures should be emphasized in the RPA from the beginning of its implementation. It is very important for both the development team and the information technology team to ensure the security of the platform and to confirm that the automation program started in the right way. In addition, it is also important to protect the reputation and operations of the GBS organization by protecting the security and privacy of data from being invaded by irresponsible individuals. 
The study also suggested for this organization to have a backup plan while implementing RPA. This is because there are respondents who expressed dissatisfaction when there is a system failure and the organization is not ready to face the situation. System failures without backup plans affect operations in the GBS organization, as well as the quality and productivity of their work. Therefore, the robotics and information technology development team should plan together with management and accountants on the implications if something does not go according to plan. That is why development standards and procedures should be made carefully no matter what happens. Organizations should create a specific RPA manual to explain the task process and steps that should be taken if the RPA fails to function (Anagnoste, 2017). Although the task has been automated, manual process control should remain within the organization and deploy to the middle and lower management levels. In addition, the business continuity plan should be constantly updated according to the new RPA process so that even during system failure occurs, the work operation process in the GBS organization can be carried out smoothly according to the latest methods and procedures. Employees in the GBS organization must also be prepared to take over the task in case something happens to the RPA infrastructure. They must take note of the task to be taken over and how to do it if this robot fails to function.

In addition, this study also suggests that organizations incorporate elements of AI into the RPA system. AI is a combination of cognitive automation, machine learning, reasoning, generating and analysing hypotheses, natural language processing, and algorithmic mutations that produce views and analysis equal to or beyond human capabilities (Kaya et al., 2019). In the future, the next phase in robotic systems will act just like humans with artificial and cognitive intelligence computing. AI will be the next stage in the RPA. Moreover, there is evidence in previous studies that in the future, all processes performed by humans including learning and decision making will be replaced by robotic systems and AI (Russell, 2016).

\section{CONCLUSION}

This study is conducted to understand the challenges of implementing RPA in the GBS industry. The research is conducted using an in-depth case study in F\&A unit. The results showed that RPA is more suitable for high volume standardized tasks that are fixed and rules-based in nature, due to the absence of AI technology in the RPA itself where there is no need for interpretative skills, analytical thinking and subjective judgement. Processes that will be robotized must have sufficient volume and transactions, as high-volume transactions allow better opportunities for organizations to get cost savings. Besides that, since RPA still requires severe guidelines to complete a task, processes that are rules-based and more precise are easier to be automated (Rozario \& Vasarhelyi, 2018; Lacity \& Willcocks, 2016). In addition, organization supposed to target the mature processes since they are more stable and predictable which consequently has a fewer risk to automate (Lacity \& Willcocks, 2016).

Hence, organization should include AI technology elements in their software to improve the RPA benefits in terms of the ability to interpret data, conduct analytical processes and conduct subjective work evaluations. Respondent in this study has stated that there are plans in the future to include AI technology elements in the RPA to further improve the effectiveness of work processes in the GBS industry. The AI element will also help these professionals to be more 
efficient and productive in performing tasks and do not have to rely on humans to make judgments.

This study helps to provide a real scenario of the challenges of implementing RPA. The findings of this study can give enlightenment to other GBS organizations that are still considering implementing RPA. In addition, this study provides enlightenment to RPA suppliers and consultants in helping to improve the quality of the system offered. The evidence reported in this study, together with previous literature can be applied in making full use of system capabilities.

The scope of this study is limited to the challenges of implementing RPA in the GBS industry. While this study has successfully exposed the challenges faced in the implementation of the RPA in the GBS industry, future studies may investigate other aspects of implementation challenges in different types of industry. In addition, future studies can use other methods such as quantitative or mixed methods in order to obtain different results. Besides that, future studies can be done by studying the correlations and relationships between RPA and other Industry 4.0 projects such as AI, factory automation, Internet of Things (IoT), mobile technology and digitization.

\section{ACKNOWLEDGEMENT}

We would like to acknowledge Universiti Kebangsaan Malaysia for funding under research grant DPK-2017-005.

\section{REFERENCES}

Agaton, B., \& Swedberg, G. (2018). Evaluating and Developing Methods to Assess Business Process Suitability for Robotic Process Automation. Department of Computer Science and Engineering.

Aman, A. (2016). Global Business Services Industry in Malaysia: With a Focus on Finance \& Accounting Shared Services. Create Space Independent Publishing.

Anagnoste, S. (2017). Robotic Automation Process-The next major revolution in terms of back office operations improvement. Proceedings of the International Conference on Business Excellence, 11(1), 676-686.

Asatiani, A., \& Penttinen, E. (2016). Turning Robotic Process Automation into Commercial Success-Case OpusCapita. Journal of Information Technology Teaching Cases, 6(2), 67-74.

Bataller, C., Jacquot, A., \& Torres S. R. (2017). Robotic Process Automation. https://www.google.com/patents/US9555544

Burnett, S., Aggarwal, M., Modi, A., \& Bhadola, S. (2018). Defining Enterprise RPA. Everest Group Research.

Fernandez, D., \& Aman, A. (2018). Impacts of Robotic Process Automation on Global Accounting Services. Asian Journal of Accounting and Governance, 9, 123-132.

Fernandez, D., Zainol, Z., \& Ahmad, H. (2018). An Investigation of Challenges in Enterprise Resource Planning (ERP) Implementation: The Case of Public Sector in Malaysia. International Journal of Supply Chain Management, 7(3), 113-117. 
Ismail, S. A., Heeks, R., Nicholson, B., \& Aman, A. (2016, June). An institutional logics perspective on IT impact sourcing: case study of a developing country public-private partnership. In European Conference on Information Systems (ECIS) 2016 Proceedings. https://www.research.manchester.ac.uk/portal/files/51518713/Instit_Logics_ITIS_PPP_ ECIS2016_Paper_Final.pdf

Jacks, T. (2017). Institutional Logics: The Next Big Challenge for Information Systems CrossCultural Research?. Journal of Global Information Technology Management, 20(1), 1-7.

Kaya, C. T., Turkyilmaz, M., \& Birol, B. (2019). Impact of RPA Technologies on Accounting Systems. Journal of Accounting \& Finance, 82, 235-250.

Lacity, M., \& Willcocks, L. (2015). Robotic Process Automation: The Next Transformation Lever for Shared Services. The Outsourcing Unit Working Research Paper Series No 16/01. http://www.umsl.edu/ lacitym/OUWP1601.pdf

Lacity, M. C. \& Willcocks, L. P. (2016). Robotic Process Automation at Telefonica O2. MIS Quarterly Executive, 15(1), 21-35.

Lacity, M. C. \& Willcocks, L. P. (2018). Innovating in Service: The Role and Management of Automation. In L. Willcocks, I. Oshri, J. Kotlarsky (Eds), Dynamic Innovation in Outsourcing (pp. 269-325). Palgrave Macmillan, Cham.

Lacity, M. C., Willcocks, L. P., \& Yan, A. (2015). Are the robots really coming? Service automation survey findings. Pulse Magazine, 17, 14-21.

Morrison, M. (2019). Risk Management in Automation of the Accounting Process. In P. Linsley, P. Shrives, \& M. Wieczorek-Kosmala (Eds.), Multiple Perspectives in Risk and Risk Management (pp. 231-239). Springer, Cham.

Ormston, R., Spencer, L., Barnard, M., \& Snape, D. (2014). The foundations of qualitative research. Qualitative research practice: A guide for social science students and researchers, 2.

Patton, M. Q. (2002). Qualitative Research and Evaluation Methods (3 $\left.{ }^{\text {rd }} \mathrm{ed}\right)$. Thousand Oaks, CA: Sage.

Penttinen, E., Kasslin, H., \& Asatiani, A. (2018, June). How to Choose Between Robotic Process Automation and Back-end System Automation? In European Conference on Information Systems 2018 (ECIS2018). Porstmouth, UK.

Rozario, A. M., \& Vasarhelyi, M. A. (2018). How robotic process automation is transforming accounting and auditing. The CPA Journal, 88(6), 46-49.

Russell, S. (2016). Should we fear supersmart robots?. Scientific American, 314(6), 58-59.

The Financial Express. (2016, August 11). Robotic process automation: The next big disruption. http://www.financialexpress.com/opinion/robotic-process-automation-the-next-bigdisruption/344032/

Walsham, G. (2006). Doing interpretive research. European journal of information systems, 15(3), 320-330.

Willcocks, L. P., Lacity, M., \& Craig, A. (2015). The IT function and robotic process automation. The Outsourcing Unit Working Research Paper Series No 15/05.

Wirtz, J., Tuzovic, S., \& Ehret, M. (2015). Global business services: Increasing specialization and integration of the world economy as drivers of economic growth. Journal of Service Management, 26(4), 565-587.

Yin, R. K. (2011). Applications of case study research. Sage publications.

Yin, R. K. (2013). Case study research: Design and methods. Sage publications. 